\title{
DISCUSSÕES ACERCA DO DISCURSO MIDIÁTICO CONTEMPORÂNEO: A FABRICAÇÃO DO CORPO MAGRO NA REVISTA ANAMARIA
}

\section{DISCUSSIONS ON THE CONTEMPORARY MEDIA DISCOURSE: THE FABRICATION OF THE SLIM BODY IN THE ANAMARIA MAGAZINE}

\author{
Suélem do Sacramento Costa de Moraes ${ }^{1}$, Bárbara Hees Garré ${ }^{2}$ \\ 1 Instituto Federal de Educação, Ciência e Tecnologia Sul-rio-grandese, Mestrado em Educação e \\ Tecnologia, Brasil, e-mail: suelemcosta@gmail.com \\ 2 Instituto Federal de Educação, Ciência e Tecnologia Sul-rio-grandese, Mestrado em Educação e \\ Tecnologia, Brasil, e-mail: barbaragarre@gmail.com
}

ART ICLE IN F O

Article history:

Received 2019-11-23

Accepted 2020-01-03

Available online 2020-02-20
Palavras-chave: Relações de poder. Corpo. Discurso midiático.

Keywords: Power relations. Body. Media discourse.

RESUMO Esse trabalho situa-se em problematizar algumas discursividades que circulam na mídia contemporânea e que fabricam o que parece ser o modelo estético vigente na atualidade, onde os corpos "devem" ser magros. Compreende-se que os corpos dos sujeitos são produzidos pelas e nas relações de poder em que estão engendrados. Toma-se como corpus empírico as reportagens da seção "Dieta" de alguns exemplares das edições semanais da revista AnaMaria, que é uma mídia impressa que operacionaliza um processo de subjetivação que funciona de um modo sutil e convidativo. Compreende-se a mídia como uma pedagogia cultural, que educa e fabrica sujeitos para além da escola. O referencial teórico e metodológico da pesquisa são alguns conceitos do filósofo Michel Foucault utilizados como ferramentas de análise.

ABSTRACT This work aims to discuss some discursivities that circulate in the contemporary media, which fabricate what seems to be the aesthetic model currently standing in society, in which bodies "must" be slim. Subjects' bodies are understood to be produced by and within the power relations in which they are inserted. The empirical corpus of this research was composed of articles from the Dieting section of AnaMaria, a magazine published in print on a weekly basis that operates via a subtle and inviting subjectivation process. The media is understood as a cultural pedagogy, that teaches and fabricates subjects beyond the schooling context. The theoretical and methodological framework for this research was composed of concepts by the philosopher Michel Foucault, which were taken as analytical tools.

\section{Anúncios Iniciais}

O texto aqui apresentado é um recorte de uma pesquisa de Dissertação de Mestrado concluída em 2018, pelo do Programa de Pós-Graduação em Educação, na linha de pesquisa Políticas e Práticas de Formação, do Instituto Federal de Educação, Ciência e 
Tecnologia Sul-rio-grandense, intitulada "O emagrecimento em discurso: Tensionamentos sobre a fabricação do corpo magro na revista AnaMaria". A investigação tem como objetivo problematizar alguns ditos hegemônicos que circulam na mídia em geral, mas especialmente na revista AnaMaria, e que subjetivam os sujeitos para que persigam, o que parece ser o padrão estético vigente, que é um corpo magro.

Organizamos este material em seções. Primeiramente apresentamos as motivações para a elaboração do trabalho, onde anunciamos o objetivo e o problema de pesquisa, bem como algumas pistas metodológicas. Logo a seguir empreendemos na articulação da nossa temática com alguns conceitos potentes do filósofo francês Michel Foucault. Em seguida, apresentamos nosso material empírico, bem como uma breve análise de algumas recorrências discursivas destacadas nos exemplares da revista AnaMaria e por fim, trazemos algumas considerações.

Neste estudo objetivamos problematizar algumas discursividades que circulam na mídia contemporânea e que fabricam o que parece ser o modelo estético vigente na atualidade, onde os corpos "devem" ser magros. Este trabalho está situado em uma vertente pós-estruturalista, no campo dos Estudos Culturais e tem como referencial teórico e metodológico alguns conceitos do filósofo francês Michel Foucault, os quais utilizamos como ferramentas analíticas.

Desse modo, com essa investigação intentamos compreender quais os efeitos que algumas fabricações discursivas produzem e que, muitas vezes, nos capturam para viver de um modo e não de outro. Muitas discursividades carregadas de significações subjetivantes sobre vários assuntos são propagadas rapidamente pela e na mídia e, nessa perspectiva, temos observado a existência de um discurso de emagrecimento sendo reverberado. Assim, nos debruçamos em nossa pesquisa na tentativa de compreender de que modo a mídia contemporânea participa da fabricação de um discurso de emagrecimento.

$\mathrm{Na}$ correnteza de alguns autores do campo dos Estudos Culturais, entende-se a mídia como uma pedagogia cultural, que produz sujeitos e subjetividades. Desse modo, "o conceito de pedagogias culturais tem sido uma ferramenta importante para que pesquisadores articulem cultura, educação e comunicação em estudos que visam problematizar a fabricação de sujeitos do tempo presente" (COSTA e ANDRADE, 2015, p.7). Assim, é também através dos artefatos midiáticos que aprendemos sobre diferentes assuntos que atravessam nossas vidas.

\section{Alguns conceitos/ferramentas que potencializam a discussão}

Como já apontamos na primeira seção, nosso objetivo de pesquisa é problematizar alguns ditos hegemônicos que versam sobre o emagrecimento e que nos incitam a adotar 
em nossas rotinas, práticas que promovam a obtenção de um corpo magro. Tais discursividades estão nos mais diversos ambientes que frequentamos e nos interpelam de um modo muito sutil, porém eficaz. Nessa perspectiva, compreendemos a necessidade de nos debruçarmos sobre alguns conceitos deixados pelo filósofo francês Michel Foucault, para a análise do nosso material empírico. Como o próprio Foucault (2006a) sugere, tomamos alguns de seus conceitos como se fossem uma caixa de ferramentas, e desta caixa nos servimos daqueles dos quais necessitamos para elaborarmos nossas articulações e problematizações.

Para começar, é importante assumirmos o conceito de discurso a partir de Michel Foucault (1999). Para ele tudo aquilo que é da ordem do visível e do enunciável é discurso. Assim, alguns ditos reverberam na sociedade, em um dado momento histórico e provocam efeitos de verdade, tais efeitos são, muitas vezes, assumidos pelos sujeitos e funcionam como verdadeiros. Além disso, é importante considerarmos que conforme Gomes (2003) a mídia produz a realidade. Desse modo, os discursos que circulam pela e na mídia fabricam o mundo em que vivemos.

Além disso, importante situar que nessa pesquisa compreendemos que somos sujeitos produzidos e fabricados não apenas pelos discursos que por nós perpassam, mas também pelas e nas relações de poder em que estamos engendrados. O poder "está em toda parte; não porque englobe tudo e sim porque provém de todos os lugares. [...] não é uma instituição nem uma estrutura [...] é o nome dado a uma situação estratégia complexa numa sociedade determinada." (FOUCAULT, 2017, p. 101). Nessa perspectiva, ocupamos diferentes posições de sujeito de uma engrenagem social que funciona constantemente. Compreendendo que para Foucault (1995), o conceito de sujeito pode ter dois significados: sujeito a outra pessoa ou sujeito a si mesmo, porém, nos dois sentidos vivemos subjetivados pelas e nas relações de poder. Assim, nós somos sujeitos fabricados, inventados e não estamos presos a uma identidade fixa, pois somos produzidos cultural e historicamente.

Importante também demarcar que nessa investigação interessa compreender como temos nossos corpos subjetivados de tal forma que acabamos incitados a perseguir um modo de ser que nos oportunize vivenciar a magreza. Segundo Oksala (2011) nossos corpos são esculpidos pelas nossas rotinas, são deturpados pelo que nos alimentamos e pelos princípios que seguimos. Nessa correnteza, tendo em vista que nosso corpo é moldado e esculpido no seio da sociedade, vimos percebendo que existe na contemporaneidade uma espécie de padronização estética, que também é construída discursiva e culturalmente.

Desse modo, somos interpelados das mais diversas formas por algumas discursividades e acabamos subjetivados a perseguir a conquista ou a manutenção de um corpo magro. Compreendemos que quando somos incitados a viver de um modo, quando 
somos interpelados pelas redes discursivas, as relações de poder estão se exercendo e nessa correnteza, atuando como uma forma de governamento dos nossos corpos.

\section{A fabricação do corpo magro na revista Anamaria}

Tomamos como corpus empírico desta pesquisa as reportagens da seção "Dieta" de alguns exemplares das edições semanais da revista AnaMaria. Essa mídia impressa é um artefato midiático bastante emblemático, que atinge um grande público, predominantemente feminino. AnaMaria é facilmente encontrada nos mais diversos ambientes, tais como supermercados, lojas de conveniências, padarias, bancas de revistas, salas de esperas de consultórios médicos, de salões de beleza, entre outros. Além disso, existe uma estratégia visual interessante operacionalizada nas capas das suas edições semanais da mídia, que é a existência de uma tarja amarela situada no lado direito e na parte superior fazendo um chamamento para a leitura da matéria da seção "Dieta".

Compreendemos que essa tarja amarela não está ali por acaso, por isso, traçamos uma analogia com as cores do semáforo, equipamento que orienta o trânsito rodoviário por meio de lanternas luminosas. Nessa perspectiva, o sinal amarelo significa "atenção", no trânsito, quando nos deparamos com o amarelo, diminuímos a velocidade do veículo e prestamos atenção, pois rapidamente o sinal mudará para vermelho e deveremos parar o carro. Desse modo, nos parece que o amarelo da tarja esteja ali naquele local de destaque na revista AnaMaria bem por essa razão, para que olhemos e prestemos atenção, para que diminuamos a velocidade e atentemos à chamada da matéria que versa sobre um discurso de emagrecimento.

A revista AnaMaria é bastante prescritiva em suas diferentes abordagens e nela encontramos diversas temáticas femininas que ensinam modos de ser e de viver para quem consome os conteúdos ali veiculados. O termo manual "caracteriza-se, em geral, pelo predomínio do discurso instrucional e didático, em que as orientações são dadas usando-se o imperativo, o infinitivo, sempre numa interlocução direta com o leitor" (COSTA, 2008, p. 131). Dessa forma, a revista AnaMaria dialoga com as suas leitoras podendo ser considerada uma espécie de manual de comportamento da mulher contemporânea. Abaixo apresentamos algumas capas da revista. 


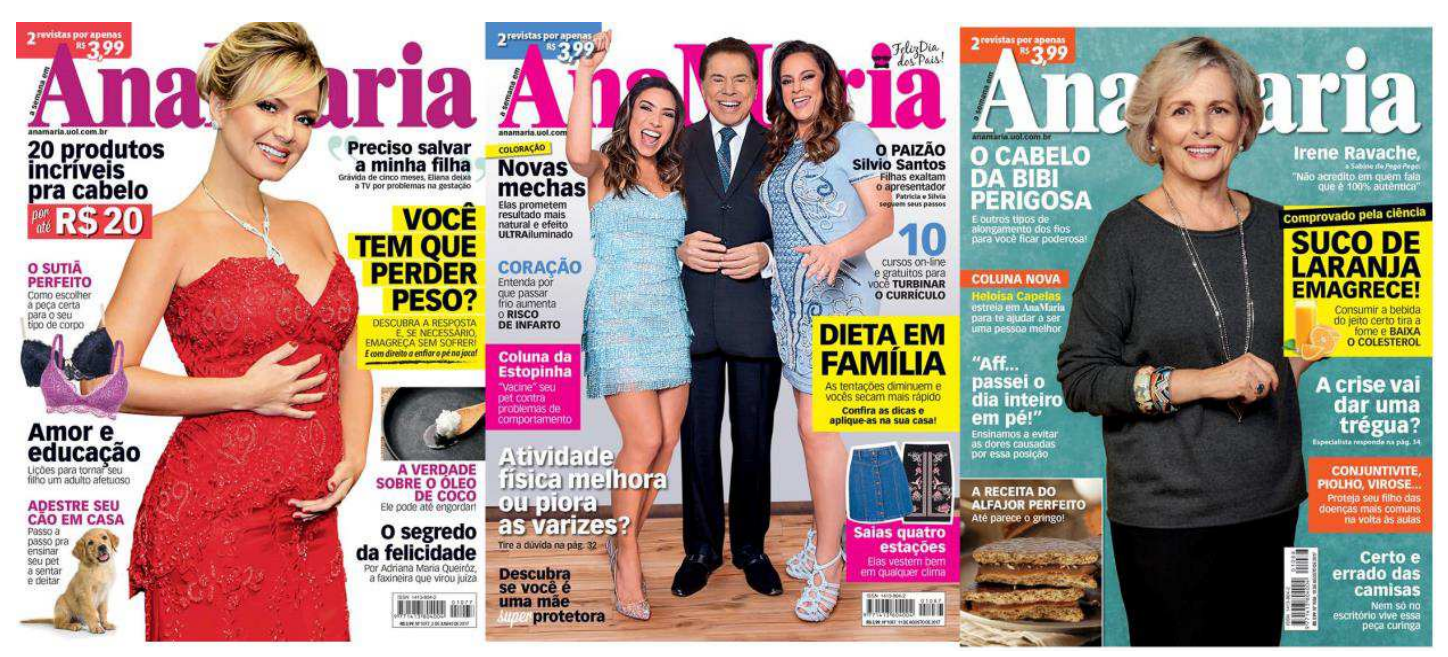

Figura 1 Ilustrações de capas da revista AnaMaria

Compreendemos que o teor da revista está muito além do foco desta pesquisa, no entanto, semanalmente encontramos algumas discursividades que incitam as leitoras para que vivam um modo de ser pautado em práticas que corroborem para a aquisição e/ou manutenção de um corpo magro. Nas edições semanais da AnaMaria, temos nos inquietado com a recorrência de um discurso de emagrecimento, que é constantemente reafirmado objetivando as leitoras a adotarem em suas rotinas práticas que oportunizem viver um modo de ser magro.

Observamos duas recorrências discursivas nas reportagens analisadas. Uma delas é a fabricação de um discurso de emagrecimento vinculado a um discurso científico legitimado por profissionais da área da saúde. As leitoras são incentivadas a adotar algumas rotinas visando a aquisição de um corpo magro e saudável. Para tanto, alguns profissionais são convocados a fazer a interlocução, ratificando os ditos da revista. Importante demarcar que compreendemos nessa pesquisa que o conceito de saúde é uma fabricação discursiva, e que existe um discurso científico, também fabricado, que é autorizado a ser proferido por alguns e não por outros, construindo também a episteme em que vivemos.

Destacamos uma enunciação em que é chamada para a discussão a voz autorizada a prescrever uma forma dita correta de nos alimentarmos, que é a da nutricionista. "Segundo J. P., nutricionista do H. R. D., é interessante ingerir alimentos que dão saciedade, para que nas refeições seguintes você não esteja com vontade de comer tudo." (AnaMaria, Dezembro de 2017, p. 25). Vemos que existe o profissional proferindo um discurso científico acerca do emagrecimento. "Sabe-se bem que não se tem o direito de dizer tudo, que não se pode falar de tudo em qualquer circunstância, que qualquer um, enfim, não pode falar de qualquer coisa" (FOUCAULT, 1999, p. 9). Percebemos, assim, que a voz da ciência é solicitada para dar autenticidade a uma dita verdade, que na perspectiva da reportagem está relacionada ao corpo magro e saudável. 
Observamos uma segunda recorrência que está situada em um forte apelo para a consciência dos indivíduos, que autorregulados, tendem a responder a uma urgência contemporânea que versa sobre o emagrecimento dos seus corpos. Esse discurso é colocado em funcionamento a partir de tecnologias disciplinares de auto disciplinamento. Extraímos as seguintes enunciações da revista para dar visibilidade ao que estamos problematizando: "Açúcar e gordura viciam. Sim, eles possuem um mecanismo viciante: quanto mais se come, mais se quer. Por isso, diminua o consumo e reeduque o paladar a gostar do sabor menos doce." (AnaMaria, Junho de 2017, p. 16). "Coma de acordo com os sinais de fome e saciedade. Não é complicado: a barriga começa a roncar, começamos a pensar mais em comida, podemos experimentar certa tontura... O corpo fala." (AnaMaria, Novembro de 2017, p. 22). "Você pode comer tudo! Veja como a culpa sabota sua dieta." (AnaMaria, Novembro de 2017, capa).

Aqui vemos estratégias de poder funcionando visando conduzir de algum modo nossas condutas e corroborando na regulação dos nossos corpos. Em poder-corpo, Michel Foucault (2006b) trata de um poder "que não tem mais a forma de controle-repressão, mas de controle-estimulação: 'Fique nu... mas seja magro, bonito, bronzeado!'” (FOUCAULT, 2006b, p. 147). Então, nos remetemos a pensar sobre nosso cotidiano e em quanto estamos o tempo todo capturados por alguma estratégia que nos disciplina, nos controla, nos subjuga e nos torna assujeitados a nós mesmos.

Com essas análises objetivamos pensar sobre o quanto as tecnologias de poder funcionam e nos interpelam a partir da mídia contemporânea, nos subjetivando a que vivamos de um modo e não de outro. Por isso, nesse estudo, pretendemos olhar com desconfiança não só para o nosso material empírico, mas também para os mais diversos ambientes por onde transitamos, colocando sob suspeita o absolutismo das certezas.

\section{Considerações Finais}

As problematizações elaboradas ao longo dessa pesquisa não pretendem apresentar respostas, elas foram lançadas para pensarmos no quanto as tecnologias de poder funcionam e nos capturam para que vivamos de uma forma e não de outra. Importante ressaltar que não estamos aqui julgando o mérito de quaisquer práticas, se elas são certas ou erradas. O que colocamos sob suspeita é a hegemonia de tais discursos que versam sobre o emagrecimento e nos convidam a viver determinadas experiências.

Desse modo, entendemos a relevância de tensionarmos a existência de uma produção discursiva que funciona como verdadeira e que constitui alguns ditos hegemônicos. Com essa pesquisa intentamos pensar sobre nossas escolhas, compreendendo que somos sujeitos subjetivados/subjetivantes, produzidos pelos discursos que por nós perpassam e engendrados nas relações de poder/saber, que fabricam as 
estruturas sociais em que vivemos.

\section{REFERÊNCIAS}

COSTA, Marisa Vorraber e ANDRADE, Paula Deporte, de. Na produtiva confluência entre educação e comunicação, as pedagogias culturais contemporâneas. 2015. Disponível em:

<https://periodicos.ufsc.br/index.php/perspectiva/article/view/32242>. Acesso em 22 ago 2018.

COSTA, Sérgio Roberto. Dicionário de gêneros textuais. Belo Horizonte. Editora Autêntica, 2008.

FOUCAULT, Michel. O Sujeito e o Poder. Apêndice da $2^{\mathrm{a}}$ Edição. Michel Foucault entrevistado por Hubert L. Dreyfus e Paul Rabinow. In.: DREYFUS, Hubert e RABINOW, Paul. Michel Foucault, uma trajetória filosófica: para além do estruturalismo e da hermenêutica. Rio de Janeiro: Editora Forense Universitária, 1995. p. 231-249.

FOUCAULT, Michel. A ordem do discurso. 5 a Edição. São Paulo. Edições Loyola, 1999.

FOUCAULT, Michel. Dos suplícios às celas. In.: POL-DROIT, Roger. Michel Foucault: Entrevistas. São Paulo: Graal, 2006a.

FOUCAULT, Michel. Poder-corpo. FOUCAULT, Michel. In.: FOUCAULT, Michel. Microfísica do Poder. 22ª Edição. Rio de Janeiro. Editora Graal, 2006b. p. 145-152.

FOUCAULT, Michel. História da Sexualidade 1: A vontade de saber. 5a Edição. Rio de Janeiro. Editora Graal, 2017.

GOMES, Mayra Rodrigues. Poder no jornalismo. São Paulo: Edusp, 2003.

OKSALA, Johanna. Como ler Foucault. Rio de Janeiro. Editora Zahar, 2011.

REVISTA AnaMaria. São Paulo. Editora Caras. Ed. 1077, 02 de Junho de 2017.

REVISTA AnaMaria. São Paulo. Editora Caras. Ed. 1104, 08 de Dezembro de 2017.

REVISTA AnaMaria. São Paulo. Editora Caras. Ed. 1107, 29 de Dezembro de 2017. 